\title{
The Impact of Pro-Social and Violent Video Games on Helping Attitude A Comparative Study
}

\author{
Justin Paolo M. Arevalo \\ Amity University Dubai \\ Aradhana Bhardwaj Balodi \\ Amity University Dubai
}

\begin{abstract}
In the beginning of the $21^{\text {st }}$ century up to the present day, the popularity of video games amongst young adults has seen a significant rise in number. The increasing popularity of video games today among individuals bears considerable impact on their behavior depending on its genre. However, most of the current literature is limited only towards the detrimental effects of video games to young adults. This study therefore aims to study the levels of helping attitude between people who play prosocial video games and those who play violent video games. The study consists of a sample of 156 individuals ages 20 and above who play pro-social and violent games. Nickell Helping Attitude Scale is used as an instrument of measure. Results were obtained using T-test and calculation of the mean. Results of the study shows that individuals who continuously play fun, light, pro-social natured games fosters empathy and helping attitude/pro-social behavior while violent video games encourage aggressive and impulsive behavior among individuals. The study helps to bring awareness to individuals and their support networks how to handle the complex impact of video games in terms of individuals' behavior, therefore mitigating any harmful and negative implications that may arise.
\end{abstract}

Keywords: helping Attitude, pro-social, video games, violent

\section{Introduction}

The increasing popularity of video games today has been a center of attention for many people today. The rapidly growing presence of console and online games all over the world is a significant source of entertainment and provides them with the opportunity to adapt in the constantly evolving technological era. Most of the present research on video games focuses on the detrimental effects it poses to the behavioral and psychological dimensions of the individual. However, despite the large presence of empirical evidence that focuses on the threat that video games carry in, current research often overlook the positive effects it carries in terms of fostering helping attitudes and pro-social behavior.

Quite a few studies examine the negative impact of video games in individuals however very few studies pertain to the positive effects of these games in terms of pro-social behavior/helping attitudes. In a research article published by Funk and Bechtold (2004), playing violent video games may result to extreme levels of desensitization of violent acts in reality and therefore decreases levels of empathy. Their research indicates that prolonged engagement to violent video games influences the player's perception of reality in which most of the time is synced with the video games they play.

However in another study carried out by Saleem, Anderson and Gentile (2012), playing video games which are neutral and nonviolent in nature improves levels of positive emotions on individuals, encouraging them to explore opportunities to interact and help people in need around them. Their research suggests that neutral and non-violent games focus mainly in cultivating helping behavior on individuals. This study is based on the Broaden and Build Theory by Barbara Fredrickson which states that the presence of positive emotions increases an individual's temporary thought and action capacity and help individuals to create strong personal resources in the future resulting to enhanced levels of positive emotions.

This study therefore examines if there is any difference in helping attitude in between people who play pro-social games and who play violent games. The study also examines whether any significant difference exists 
between males and females in terms of helping attitude.

\section{Literature Review}

In a study conducted by Anderson and Bushman (2011), adventure games which require players to interact with other players online can help foster helping attitude amongst individuals. The study have shown that individuals who prefer playing role playing games (RPG) such as Final Fantasy (a game that requires players to cooperate with others to advance in the plot of the game) report better teamwork and coordination skills in their daily activities compared to those who prefer playing solo oriented games. Video games that allow players to connect with other players to fulfill the objectives of the game are more likely to mirror these experiences in the real world and therefore strengthen social relationships with others.

In an empirical study conducted by Wiegman and Schie (2011), pro-social video games characterized by the act of helping other players to complete the game or working together towards the same goal in the game fosters strong interpersonal relationships with players leading to high levels of helping behavior. The results of their study indicate that video games which encourage cooperating with others help them to form strong relationships and motivate them to help others in need not only in the game but in reality as well. According to them, the chain effect is strengthened or weakened by their levels of attachment and interest in playing pro-social video games.

In another research conducted by Vogel and Bowers (2006), suggest how pro-social video games that involve simulation of helping attitudes not only promote awareness about the importance of pro-social behavior but also encourage imitating them in reality. Results of their research indicate that games like Farmville or Sims which are based on actual human behavior in certain situations, helps individuals to see the benefit of adopting helping behaviors in reality. For instance, the games' features involve the act of helping neighbors in need or a friend in distress and the game rewards the players when such action is completed, providing reinforcement which mirrors a real life scenario. Furthermore, such simulation games also provide a constant source of entertainment and stimulation at the same time, reinforcing learning in a fun and interactive way.

However, a research article published by Carnegey and Anderson (2005) states that video games that encourage online competitions which involve elimination of the other teams participating, increases feelings of hostility towards other players and such hostility is reflected in their relationships with peers. For instance, results of the study have shown that students who prefer playing games like Call of Duty or Counter Strike with other students (shooting games which have team elimination features) have reported to have more hostile feelings towards other people who they perceive as competition or adversaries in real life. These feelings of hostility overtime can foster hatred towards others during important events like a Sports Festival in colleges.

Another research conducted by Grusser, Thalemann and Griffiths (2007) suggests that violent video games which require players to be quite skilled often results to angry behavior and aggression. Research findings have shown that students who play these kinds of video games are more likely to experience rage while playing, a behavior characterized by angry, violent and sudden outbursts of the player when they experience a situation in the game that they do not like to happen. Such behavior often involves destroying the console where the game is played, punching walls and other irrational behavior. Findings suggest that the more important the goal in the game is, the more "rage" is expressed when players are unable to achieve that goal.

\section{Methodology \\ Objective}

- To study the difference if any, in helping attitude in between people who play prosocial games and who play violent games

- To study the difference if any, in helping attitude between males and females

\section{Hypotheses}

H1: There is no significant difference in helping attitude in between people who play pro-social games and who play violent games $\mathrm{H} 2$ : There is no significant difference between males and females in terms of helping attitude 


\section{Locale of the Study}

The data was collected from Amity University Dubai, colleagues from internships in Avenue Car Rental and Limousine in Al Quoz, close friends and the local neighborhood of Bur Dubai.

\section{Sampling Design}

The present investigation adopts a purposive sampling method of data collection.

\section{Research Design}

Comparative research design has been used for the present investigation. A comparative research refers to a commonly used method of research in the field of social sciences used to identify and compare the similarities and differences across different concepts, topics and ideas (Hantrais, 1995). The present investigation is a comparative study of helping attitude in between pro-social gamers and violent gamers.

Sample and Its Selection

Individuals of age 20 and above are selected to be a part of the sample. A total of 156 individuals were assessed; 82 of whom play pro-social games and 78 who play violent games.

\section{Inclusion Criteria}

The study consists of individuals ages 20 and above who play pro-social and violent games.

\section{Description of Tool Employed}

The Nickell Helping Attitude Scale is a twenty-item questionnaire that measures an individual's perception and feelings associated with the act of aiding others. The scale uses a 5-point Likert scale, from 1 (strongly disagree) to 5 (strongly agree). 409 undergraduate students were selected to be a part of the sample and their psychological properties were then measured. The scale has direct, positive correlation with levels of empathy, social responsibility, and altruism. However, the scale shared an inverse relationship with selfishness. The scale was found to have high levels of reliability and validity through a number of preliminary studies with internal reliability of 0.76 .

\section{Scoring}

The test consists of 20 items and the subject is asked to rate the statements based on the 5point scale provided. The test consists of positive and negative statements. Items $1,5,8$, 11,18 and 19 are negative items and are reversely scored. The scores for each item are added up together to form an overall score, ranging from 20 to 100 . According to the author, 60 is a neutral score.

\begin{tabular}{|c|c|c|c|c|}
\hline 1 & 2 & 3 & 4 & 5 \\
\hline $\begin{array}{c}\text { Strongly } \\
\text { Disagree }\end{array}$ & Disagree & Undecided & Agree & $\begin{array}{c}\text { Strongly } \\
\text { Agree }\end{array}$ \\
\hline
\end{tabular}

Procedure

Prior on the test's conduction, good rapport was built with the respondents and environmental factors were taken care off to ensure the respondents' comfort. Instructions were explained to the subjects carefully and it all doubts that the respondents may have been cleared. The purpose of the study and prosocial behavior/helping attitude as a construct were explained to the subject to ensure clarity. The scores of were recorded and tabulated. Furthermore, the mean and standard deviation of both groups was calculated furthermore, t-test will be done to verify the hypothesis.

\section{Result Analysis}

Table 1: Mean and Standard Deviation of Both Pro-Social and Violent Gamers

\begin{tabular}{|c|c|c|c|c|c|}
\hline & $\begin{array}{l}\text { Type of } \\
\text { Gamer }\end{array}$ & $\mathrm{N}$ & Mean & $\begin{array}{l}\text { Std. } \\
\text { Deviation }\end{array}$ & $\begin{array}{l}\text { Std. } \\
\text { Error } \\
\text { Mean }\end{array}$ \\
\hline \multirow[t]{2}{*}{$\begin{array}{l}\text { Helping } \\
\text { Attitude }\end{array}$} & $\begin{array}{l}\text { Pro- } \\
\text { social } \\
\text { Gamer }\end{array}$ & 82 & 79.34 & 6.737 & .744 \\
\hline & $\begin{array}{l}\text { Violent } \\
\text { Gamer }\end{array}$ & 78 & 48.99 & 7.185 & .814 \\
\hline
\end{tabular}

As per the above table, the mean for pro-social gamers shows a value of 79.34 and a standard deviation 6.737 while the mean value for violent gamers is 48.99 with a standard deviation of 7.185 . The results given in the table clearly shows that on average, pro-social gamers have higher tendencies to adopt helping attitudes than violent gamers.

Table 2: Mean and Standard Deviation in Terms of Gender Differences

\begin{tabular}{|c|c|c|c|c|c|}
\hline & Gender & $\mathrm{N}$ & Mean & $\begin{array}{l}\text { Std. } \\
\text { Deviation }\end{array}$ & $\begin{array}{l}\text { Std. } \\
\text { Error } \\
\text { Mean }\end{array}$ \\
\hline Helping & Males & 118 & 63.42 & 16.419 & 1.511 \\
\hline Attitude & Females & 42 & 67.69 & 17.376 & 2.681 \\
\hline
\end{tabular}

As per the table given above, the mean for male gamers shows a value of 63.42 and a 
standard deviation of 16.419 while the mean value for female gamers is 67.69 with a standard deviation of 17.376. Results of the table suggest that there is no difference in terms of gender with regards to helping attitude.

Table 3: Main Table to Depict Group Difference on Pro-social Attitude with respect to Type of Gamers and Gender

\begin{tabular}{llll}
\hline Criterion for & & & Mean \\
differentiation & $\mathrm{T}$ & df & Difference \\
\hline Type of Gamer & $27.579^{* *}$ & 158 & 30.354 \\
Gender & -1.424 & 158 & -4.267 \\
\hline
\end{tabular}

${ }^{* *} \mathrm{p}<.01$

As per the table given above, with respect to the type of gamer, the $t$ value is $27.579 p<.01$ with df (158). This result shows that people who play pro-social games differ significantly from those who play violent games in terms of helping attitude.

With respect to gender, the $t$ value is 1.424 $\mathrm{p}=.17$ with $\mathrm{df}$ (158). This result shows that men and women video game players do not significantly differ in terms of helping attitude.

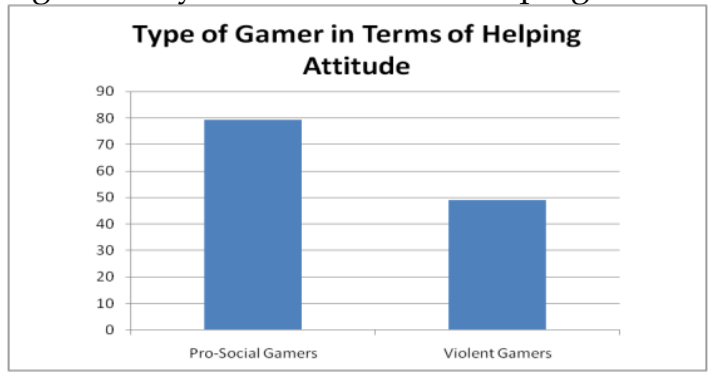

Figure 1: Graphical Representation showing Helping Attitude Between Pro-social Gamers and Violent Gamers

According to Figure 1 given above, results show that on average, pro-social gamers engage in more helping attitude than violent gamers.

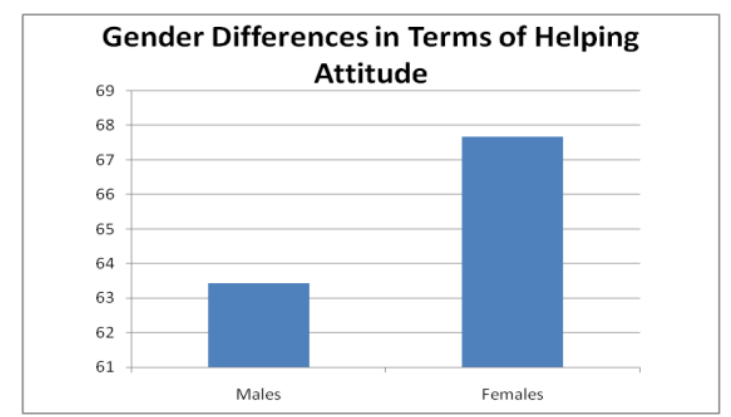

Figure 2: Graphical Representation showing Helping Attitude Between Males and Females
According to Figure 2 given above, there is no significant difference in the mean between males and females in terms of helping attitude

\section{Discussion}

The study highlights how individuals who play pro-social games have a higher tendency to adopt helping attitudes compared to individuals who play violent games. Pro-social games (such as Sudoku, Minecraft, Sims, Farmville, Final Fantasy and other non-violent simulation games) encourage gamers to cooperate and help friends and people in need, acting as a stimulator for helping behavior and attitude (Anderson \& Bushman, 2011). These games act as a "role model" in instigating helping attitudes such as comforting a friend in distress or adversity, increasing levels of emotional intelligence and sensitivity towards others (Vogel \& Bowers, 2006). Furthermore, pro-social video games have seen to increase the interest to engage in meaningful interpersonal relationships characterized by a more communal (genuine concern) approach towards interacting with others and thus nurturing high levels of pro-social behavior and helping attitude (Wiegman \& Schie, 2011).

The results of this study integrate findings with various sources of current literature which suggests that individuals who play prosocial games have higher levels of pro-social behavior/helping attitude compared to individuals who play violent games and there is no significant difference in terms of gender. Limitations of the Study

This study is limited only to individuals age 20 and above and therefore does not include other age groups below the said age bracket. In addition, the current sample consists of a predominantly large number of male respondents who play pro-social and violent video games. The number of males and females in the sample are not equally distributed.

\section{Conclusion and Future Study}

The aim of the present study is to examine the levels of helping attitude/pro-social behavior between individuals who play pro-social games and individuals who play games which are violent in nature. Results of the present study show that individuals who play prosocial games have a tendency to engage in prosocial behavior compared to individuals who 
play violent games. The sample of individuals who play pro-social games have increased awareness about the importance of teamwork and cooperation in the games they play which is in turn imitated in terms of their relationships with others in the real world, reinforcing high levels of helping attitude and pro-social behavior (Vogel \& Bowers, 2006). The present study suggests that individuals who continuously spend their time playing pro-social games are more willing and likely to help others in times of need and distress compared to individuals who indulge themselves playing violent games which foster aggression and angry behavior (Grusser, Thalemann and Griffiths, 2007). Therefore, the present study indicates that there is significant difference in helping attitude in between people who play pro-social games and who play violent video games. In addition, results of the present study also show that there is no significant difference between males and females in terms of helping attitude.

Due to the limited age bracket included in the sample, future research on this topic could have the inclusion of a larger and more diverse sample age. Furthermore, since the study consists of a predominantly large number of male respondents, further research on the topic could have a relatively balanced sample of males and females in order to mitigate the effects of bias in future researches. The present study can help future researchers to inhibit the violent effects of video games and encourage helping attitude among individuals

\section{References}

Anderson, C. \& Bushman, B. (2011). Effects of Violent Video Games on Aggressive Behavior, Aggressive Cognition, Aggressive Affect, Physiological Arousal, and Pro-social Behavior: A Meta-Analytic Review of the Scientific Literature. Sage Journals, 12 (3), 24-29.

Carnegey, N. \& Anderson, C. (2005). The Effects of Reward and Punishment in Violent Video Games on Aggressive Affect, Cognition, and Behavior. Journal of Aggressive Behavior, 6 (6), 56-60.

Funk, B. \& Bechtold, H. (2004). Violence exposure in real-life, video games, television, movies, and the internet: is there desensitization?. Journal of Adolescence, 27 (1), 23-29.

Grusser, D., Thalemann, R. \& Griffiths, D. (2007). Excessive Computer Game Playing: Evidence for Addiction and Aggression?. Cyber Psychology and Behavior, 10 (2), 45-49.

Hantrais, L. (1995). Comparative Research Methods. Social Research Update, 2 (13). Retrieved from: http://sru.soc.surrey.ac.uk/SRU13.html

Saleem, A., Anderson, C \& Gentile, A. (2012). Effects of Pro-social, Neutral, and Violent Video Games on College Students' Affect. Journal of Aggressive Behavior, 20 (3), 34-38.

Vogel, J. \& Bowers, C. (2006). Computer Gaming and Interactive Simulations for Learning: A Meta-Analysis. Sage Journals, 5 (3), 12-18. Retrieved from: https://doi.org/10.2190/FLHV-K4WAWPVQ-HOYM

Wiegman, O. \& Schie, E. (2011). Video game playing and its relations with aggressive and prosocial behaviour. Journal of Adolescence, 12 (5), 32-37. 